Supporting information

\title{
Losing the Expression of Molecular Chirality in Self-Assembled
}

\section{Physisorbed Monolayers}

Jian Zhang, André Gesquière, Michel Sieffert, Markus Klapper, Klaus Müllen, Frans C. De Schryver, Steven De Feyter*

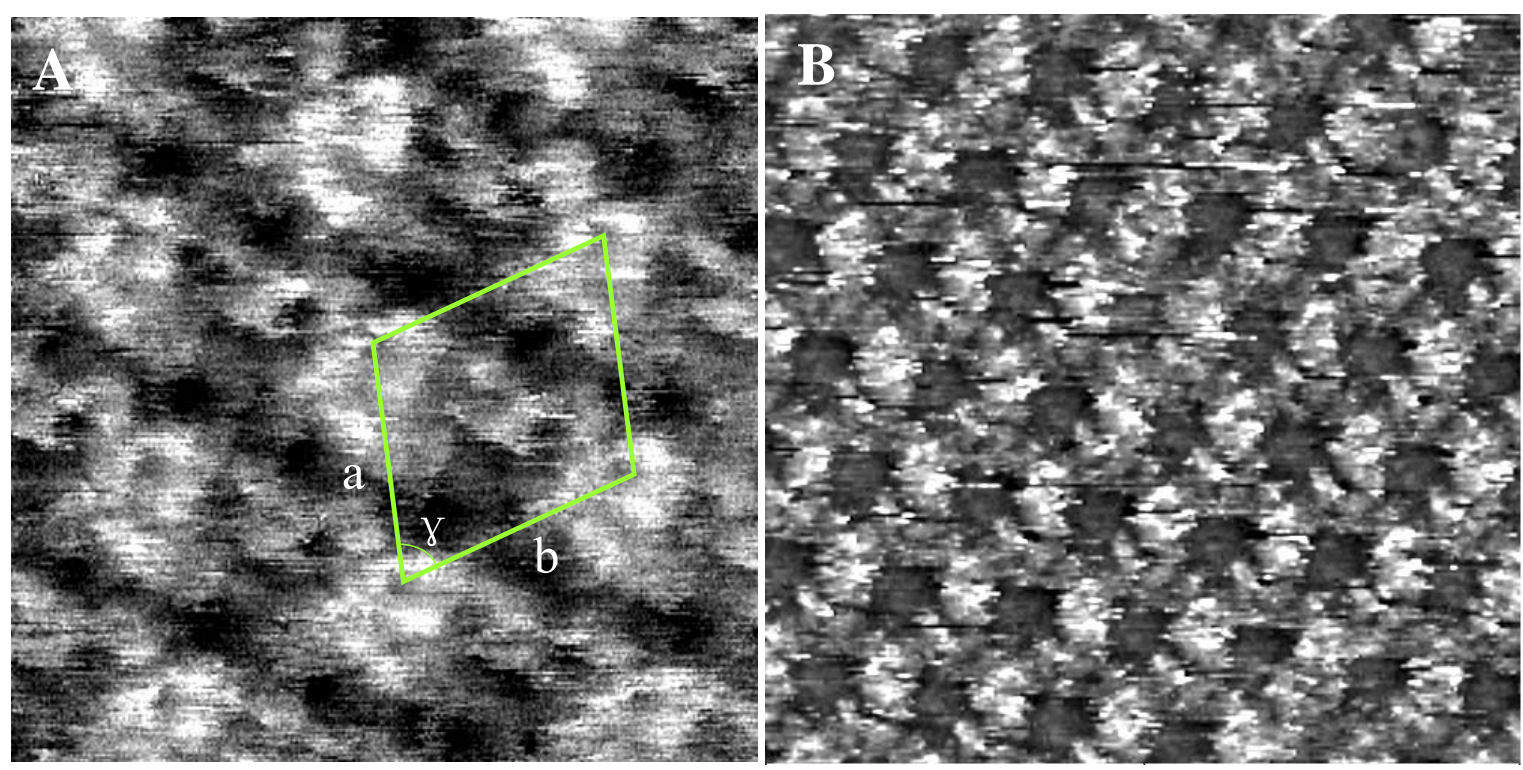

Figure 1. STM image of a monolayer of (S)-1 formed by physisorption at the 1,2,4-trichlorobenzene/graphite interface, showing the hexagonal-type packing. (A) Image size: $9.5 \times 9.5 \mathrm{~nm}^{2}, I_{\text {set }}=0.46 \mathrm{nA}, V_{\text {bias }}=-1.09 \mathrm{~V}$. The unit cell is indicated in green: $\mathrm{a}=3.58 \pm 0.13 \mathrm{~nm}, \mathrm{~b}=3.60 \pm 0.10 \mathrm{~nm}, \gamma=59.4 \pm 0.5^{\circ}$ (B) Image size: $22.7 \times 22.7$ $\mathrm{nm}^{2}, I_{\text {set }}=0.46 \mathrm{nA}, V_{\text {bias }}=-0.72 \mathrm{~V}$. 